\title{
Study of pregnancy with disseminated intravascular coagulation
}

\author{
Satishchandra K. Kadikar ${ }^{1}$, Farheenbanu J. Diwan ${ }^{1}$, Usmaan Topiwala ${ }^{2 *}$, Saliha Agasiwala ${ }^{1}$
}

${ }^{1}$ Department of Obstetrics and Gynecology, ${ }^{2} \mathrm{MBBS}$ Student, Smt. SCL Hospital, Ahmedabad, Gujarat, India

Received: 26 August 2021

Revised: 04 October 2021

Accepted: 05 October 2021

\section{*Correspondence:}

Dr. Usmaan Topiwala,

E-mail: topiwalausmaan@gmail.com

Copyright: ( ) the author(s), publisher and licensee Medip Academy. This is an open-access article distributed under the terms of the Creative Commons Attribution Non-Commercial License, which permits unrestricted non-commercial use, distribution, and reproduction in any medium, provided the original work is properly cited.

\section{ABSTRACT}

Background: At present time, obstetric bleeding remains to be the world's main cause of maternal mortality, early identification of factors leading to haemorrhage and early management of underlying pathological process is the key stone of the treatment. The most important pregnancy related condition leading to bleeding with high maternal mortality and morbidity rate is disseminated intravascular coagulation (DIC).

Methods: A prospective study of 50 cases of pregnancy with DIC was performed from May 2018 to November 2020 in our institute to detect the various aetiology and complications associated with DIC leading to maternal mortality and morbidity and study perinatal outcome in pregnant women with DIC.

Results: The prevalence of DIC in our institute is $0.22 \%$. Common causes of DIC were abruption (36\%), haemorrhage $(34 \%)$, preeclampsia $(18 \%)$, sepsis $(6 \%)$ and acute hepatic failure $(6 \%)$. The composite severe maternal morbidity outcome in haemorrhage (100\%), abruption (63\%), preeclampsia (58\%), and AVH (33\%).Out of the three most common causes (abruption, haemorrhage and preeclampsia), the composite maternal morbidity outcome was significantly more in women with haemorrhage than with abruption and preeclampsia.

Conclusions: DIC, as a marker of severe obstetrical complications, is associated with high levels of mortality and morbidity. Recognition of the antecedent causes and early investigation for and active management of DIC may help lower this morbidity.

Keywords: Disseminated intravascular coagulation in pregnancy, Maternal morbidity and mortality

\section{INTRODUCTION}

At present time, obstetric bleeding remain to be the world's main cause of maternal mortality, early identification of factors leading to haemorrhage and early management of underlying pathological process is the key stone of the treatment. The most important pregnancy related condition leading to bleeding with high maternal mortality and morbidity rate is disseminated intravascular coagulation. ${ }^{1-3}$

The danger surroundings obstetrical disseminated intravascular coagulation were recognized and described as early as 1901 by Joseph DeLee, in a fatal case of haemorrhagic diathesis with placental abruption. ${ }^{4}$ As per definition of International society of Thrombosis and
Haemostasis, DIC is defined as: An acquired syndrome characterised by intravascular activation of coagulation with loss of localization arising from different causes. ${ }^{5,6}$

It can originate from and cause damage to the microvasculature, which is sufficiently severe to produce organ dysfunction. DIC is estimated to be present in as many as $1 \%$ of hospitalised patients. DIC is always secondary phenomenon and ranging from obstetrical accidents to malignancy. ${ }^{6}$

Obstetrical condition associated with DIC include Abruption, placenta previa, severe preeclampsia/eclampsia, HELLP syndrome, PPH, retained dead fetus, delayed miscarriage, septicaemia , amniotic fluid embolism, and acute fatty liver of pregnancy. ${ }^{7-9}$ 
The pathophysiology of DIC involved a systemic activation of coagulation followed by widespread fibrin deposition, microvascular thrombosis and organ failure. ${ }^{10}$

Clinically, DIC can present anywhere along the spectrum from thrombosis and micro vascular damage to overt and uncontrolled bleeding. By identifying antecedents associated with obstetrics DIC clinicians may be better prepared to diagnose and initiate early management of this life threatening condition. ${ }^{11}$

DIC was reported to be the second most common severe maternal morbidity indicator. It was associated with nearly $1 / 4^{\text {th }}$ of maternal death. Study done by Cunningham in 2015 causes for DIC were abruption 1:200, AFE 2:10000, acute fatty liver of pregnancy 1:10000, massive obstetric haemorrhage 23 to $30: 1000$ and sepsis. ${ }^{12}$ Complications with DIC are bleeding, shock, acute renal failure, pleural effusion, pulmonary oedema, haematuria, hepatic encephalopathy, cardiac arrest, hypoxic brain damage etc. $^{13}$

Here we performed a prospective study of 50 cases of pregnancy with DIC from May 2018 to November 2020 in our institute to detect the various aetiology and complications associated with DIC leading to maternal mortality and morbidity and study perinatal outcome in pregnant women with DIC.

The above study was compared with study done by Rattray et al. ${ }^{14}$

\section{Aims and objectives}

To study the prevalence of DIC in our institute and know aetiology and contributing factors responsible for DIC. To study maternal and perinatal morbidity and mortality.

\section{METHODS}

It was a prospective cross sectional study conducted at Smt. SCL Hospital, Ahmedabad, Gujarat, India for a period of May 2018 to November 2020.

\section{Inclusion criteria}

Indoor pregnant women suffering from DIC admitted in Smt. SCL Hospital.

\section{Exclusion criteria}

Pregnant women with bleeding or coagulative disorders.

\section{Procedure}

The total number of antenatal indoor patient during this period was 23014. Out of which approximately 50 cases of DIC were diagnosed. Demographics of the affected woman collected including age, parity, education, socioeconomical status, address, gestational age at delivery, mode of delivery, days in hospital and maternal weight. The laboratory tests include routine test (complete blood count, blood group, blood sugar, urine routine microscopy and HIV/HBsAg status), DIC specific test are platelet count, PTINR, aPTT, PTINR/aPTT, serum fibrinogen, BTCT, FDP and D dimer. The presence of overt DIC was determining by using ISTH DIC scoring system, which assigns points on the basis of decreasing platelet count, prolonged prothrombin time, elevated fibrin related marker and fibrinogen level.

International society for Thrombosis and Haemostasis (ISTH) disseminated intravascular coagulation scoring system used only in patient with underlying condition known to be associated with DIC. ${ }^{14,15}$ Overt DIC $>5$ points, non-overt DIC $<5$ points.

Table 1: ISTH DIC scoring system.

\begin{tabular}{|llll|}
\hline & 0 & 1 & 2 \\
\hline Thrombocytopenia & $>100,000 / \mathrm{mm}^{3}$ & $\leq 100,000 / \mathrm{mm}^{3}$ & $\leq 50,000 / \mathrm{mm}^{3}$ \\
\hline D-dimer & Normal & $\leq 10$ times ULN & $\geq 10$ times ULN \\
\hline PT prolongation & $<3$ seconds & $3-6$ seconds & 6 seconds \\
\hline Fibrinogen & $>100 \mathrm{mg} / \mathrm{dl}$ & $\leq 100 \mathrm{mg} / \mathrm{dl}$ & \\
\hline
\end{tabular}

Ethical approval was taken from the institutional ethics committee.

\section{Statistical analysis}

Data was analysed using Microsoft excel.

\section{RESULTS}

The prevalence of DIC in our institute was $0.22 \%$. In present study, $18(36 \%)$ were booked and $32(64 \%)$ were emergency patients, incidence of DIC was higher in emergency patients. Maximum numbers of patients were found between the ages of 20 to 30 years (84\%) which is the reproductive age group. DIC was developed in $1(02 \%)$ antenatal and $49(98 \%)$ postnatal patient. Common causes of DIC were abruption (36\%), haemorrhage (34\%), preeclampsia (18\%), sepsis (6\%) and acute hepatic failure $(6 \%)$. Out of 49 patients, $13(26 \%)$ were delivered vaginally and $36(74 \%)$ undergone for caesarean section. In vaginal delivery DIC is mostly due to atonic PPH and septicaemia, while in caesarean section DIC due to 
abruption, placenta previa and intrapartum haemorrhage. Most common indications of caesarean were abruption, placenta previa and severe preeclampsia/eclampsia. In all these cases caesarean was mandatory.

Table 2: DIC antecedents and maternal outcome in present study.

\begin{tabular}{|lllllll|}
\hline Antecedents & Abruption (18) & Haemorrhage (17) & Preeclampsia (09) & AHF (03) & Sepsis (03) & Total (50) \\
\hline Ceserean section & 15 & 12 & 07 & 02 & 00 & $36(73 \%)$ \\
\hline Vaginal delivery & 03 & 05 & 02 & 01 & 02 & $13(26 \%)$ \\
\hline Massive transfusion & 09 & 10 & 01 & 01 & 00 & $21(42 \%)$ \\
\hline Hystrectomy & 00 & 09 & 00 & 00 & 00 & $09(18 \%)$ \\
\hline ICU admission & 04 & 05 & 05 & 02 & 03 & $22(44 \%)$ \\
\hline Dialysis & 01 & 01 & 01 & 01 & 00 & $04(8 \%)$ \\
\hline Maternal death & 00 & 04 & 03 & 00 & 01 & $08(16 \%)$ \\
\hline Composite outcome & $12(63 \%)$ & $18(100 \%)$ & $04(58 \%)$ & $01(33 \%)$ & $00(00 \%)$ & $30(60 \%)$ \\
\hline
\end{tabular}

Table 3: Mode of treatment in DIC.

\begin{tabular}{|lllllll|}
\hline Causes & $\begin{array}{l}\text { Abruption } \\
(\mathbf{1 8})\end{array}$ & $\begin{array}{l}\text { Haemorrhage } \\
(\mathbf{1 7})\end{array}$ & Preeclampsia (9) & $\begin{array}{l}\text { AHF } \\
(\mathbf{3})\end{array}$ & $\begin{array}{l}\text { Sepsis } \\
(\mathbf{3})\end{array}$ & $\begin{array}{l}\text { Total } \\
(\mathbf{5 0})\end{array}$ \\
\hline Medical management & & & & & & \\
\hline Oxytocin & 18 & 17 & 09 & 03 & 03 & $33(100 \%)$ \\
\hline Misoprostol & 09 & 11 & 03 & 01 & 00 & $24(48 \%)$ \\
\hline Ergometrine & 02 & 04 & 02 & 01 & 00 & $06(18 \%)$ \\
\hline 15 methyl prostaglinds & 05 & 07 & 05 & 00 & 00 & $17(34 \%)$ \\
\hline Inotropic support & 05 & 08 & 03 & 02 & 02 & $20(40 \%)$ \\
\hline Antibiotics & 18 & 17 & 9 & 3 & 3 & $50(100 \%)$ \\
\hline Surgical management & & & & & & \\
\hline Hysterectomy & 00 & 09 & 00 & 00 & 00 & $09(18 \%)$ \\
\hline Uterine tamponade & 02 & 03 & 01 & 00 & 00 & $06(12 \%)$ \\
\hline Uterine compression sutures & 03 & 02 & 00 & 00 & 00 & $5(10 \%)$ \\
\hline Major vessel ligation & 01 & 02 & 00 & 00 & 00 & $03(6 \%)$ \\
\hline Embolization & 00 & 00 & 00 & 00 & 00 & $00(00 \%)$ \\
\hline Blood products & & & & & & \\
\hline Blood & 70 & 74 & 20 & 08 & 05 & 177 \\
\hline Fresh frozen plasma & 72 & 90 & 32 & 24 & 00 & 218 \\
\hline Cryoprecipitate & 12 & 16 & 08 & 00 & 00 & 36 \\
\hline Platelets & 108 & 81 & 36 & 08 & 00 & 233 \\
\hline Albumin & 00 & 01 & 00 & 01 & 00 & 02 \\
\hline
\end{tabular}

Table 4: DIC antecedents and perinatal outcome in present study.

\begin{tabular}{|lllllll|}
\hline Antecedents & Abruption (18) & Haemorrhage (19) & Preeclampsia (9) & AHF (3) & Sepsis (2) & Total (51) \\
\hline Infant survived & 09 & 19 & 07 & 03 & 02 & $39(76 \%)$ \\
\hline Neonatal death & 00 & 04 & 02 & 01 & 00 & $07(18 \%)$ \\
\hline Intrauterine death & 11 & 00 & 01 & 00 & 00 & $12(24 \%)$ \\
\hline Nicu admission & 05 & 08 & 05 & 02 & 01 & $21(42 \%)$ \\
\hline Nbw & 10 & 12 & 06 & 02 & 02 & $32(54 \%)$ \\
\hline Lbw & 06 & 06 & 02 & 01 & 00 & $15(29 \%)$ \\
\hline Vlbw & 02 & 01 & 01 & 00 & 00 & $04(8 \%)$ \\
\hline
\end{tabular}

The DIC severity score (by ISTH DIC scoring system) for each cause were calculated and categorised into non overt and overt DIC. Percentage of non-overt DIC was $66 \%$ and overt DIC was 34\%. Maternal outcome was worst in overt
DIC. There was no statistical difference between the severity of DIC and obstetrical causes in our study. ${ }^{14}$

In present study, caesarean section done in $36(73 \%)$ and vaginal delivery in $13(26 \%)$ patients, ICU admission 
required in $22(44 \%)$ patients, massive blood transfusion was given in $21(42 \%)$ patients, hysterectomy done in 8 (16\%) patients and dialysis in $4(8 \%)$ patients. Need of massive blood transfusion is higher in haemorrhage $(85 \%)$ and abruption (56\%) compared to other causes.

Total $9(18 \%)$ hysterectomy were performed, 7 (78\%) due to intrapartum haemorrhage and $2(22 \%)$ rupture uterus, 4 $(8 \%)$ dialysis required in cases of acute renal failure.

Medical treatment, surgical treatment and blood product replacement were used in majority of cases which is outlined in the Table 3.

Medical treatment is given in form of uterotonics \{ oxytocin (100\%), misoprostol (48\%), ergometrine (18\%) and prostaglandins (34\%) $\}$, antibiotics (100\%) and inotropic support (40\%).

Surgical management include hysterectomy (18\%), uterine tamponade (12\%), uterine compression sutures (10\%), major vessel ligation $(06 \%)$.

Almost all the patients were given blood and blood products. Rate of blood and blood products transfusion were highest in haemorrhage followed by abruption.

(Total number of blood 177 unit and blood products 487 units were given in 50 patients so on an average 3.5 blood unit in one patient was required).

There were two twin pregnancy and total 51 infants were born by 49 mothers out of whom $37(70 \%)$ infants survived, $13(25 \%)$ died in utero. $21(53 \%)$ required NICU admission.

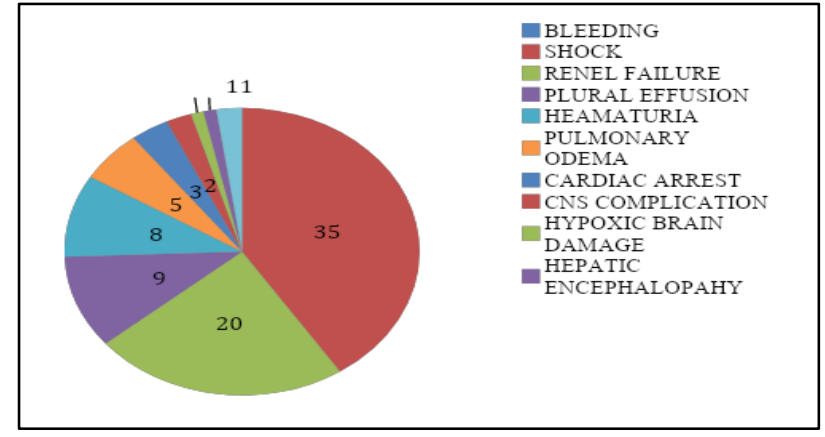

Figure 1: Complications in patients with DIC.

Out of 39 neonates, 7 (18\%) neonates were died. Common causes of mortality were prematurity, LBW and septicaemia, 32 (54\%) having normal birth weight, 15 (29\%) having low birth weight and 04 (8\%) having very low birth weight.

In our study, total 8 maternal deaths occur with case fatality of $16 \%$ which means out of 6 patients 1 was prone to death. Out of 8 , only $2(20 \%)$ were booked patient and $6(80 \%)$ were emergency patients.

Case fatality rate was higher in emergency patient (10\%) compared to booked patient $(6 \%)$ suggesting that lack of antenatal care affect maternal outcome. Most common cause of death was haemorrhage (50\%).

\section{DISCUSSION}

Prevalence of DIC in our institute during study period from May 2018 to November 2020 was $0.22 \%$. Because of many definitions and variable degree of severity accurate incidence of DIC is not known but it ranges from $0.03 \%$ to $0.35 \% .^{14}$

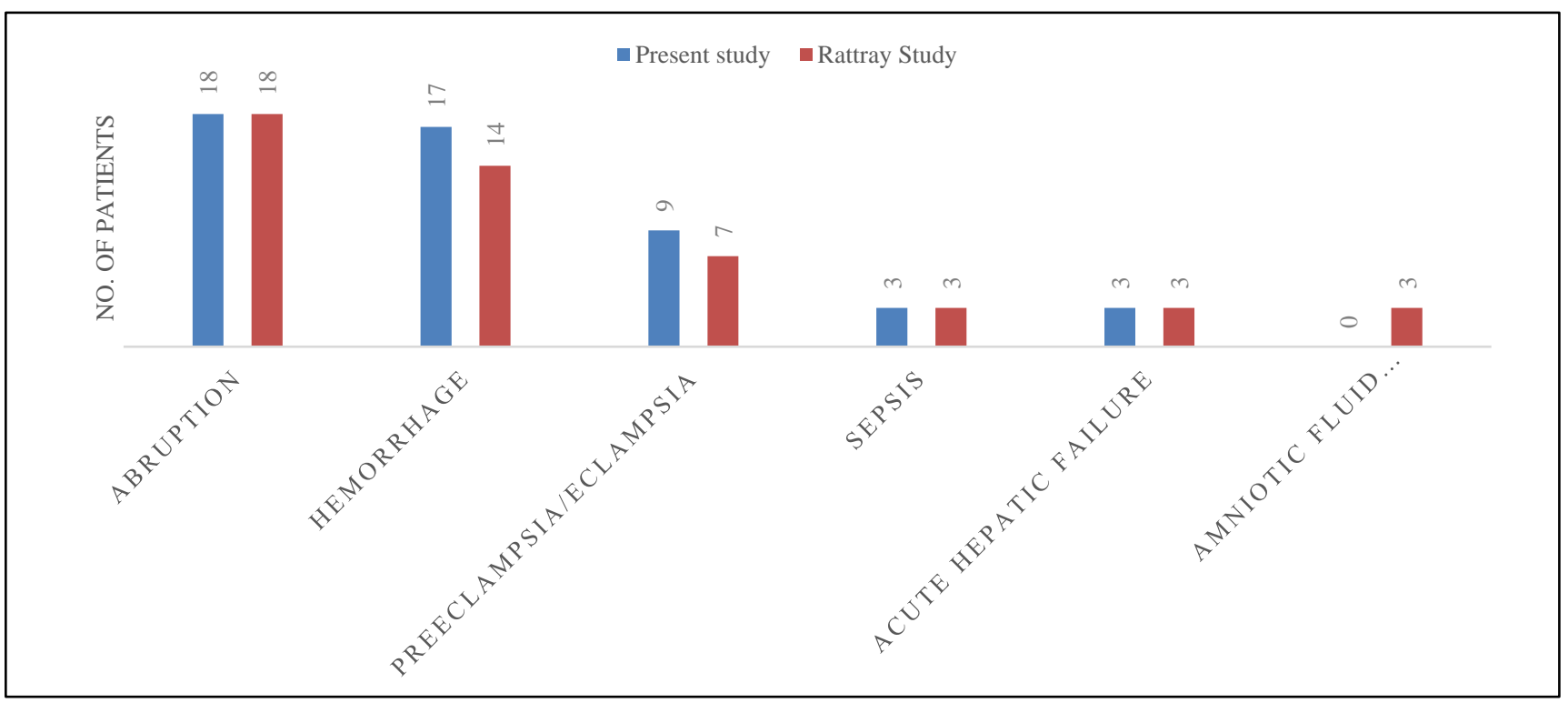

Figure 2: Comparison of causes of DIC. 
Our study compared with study done by Rattray et al. ${ }^{14}$ Major causes of DIC in present study abruption (36\%), haemorrhage (34\%), preeclampsia $(18 \%)$, sepsis $(6 \%)$, acute hepatic failure $(6 \%)$. Here haemorrhage includes blood loss due to placenta previa, uterine atonicity or genital tract trauma. No case of AFE found in my study. In study done by Rattray et al causes of DIC were abruption $(37 \%)$, PPH $(29 \%)$, preeclampsia $(14 \%)$, sepsis $(6 \%)$, AVH (8\%), which was matched with our study. ${ }^{14}$

In present study, caesarean section done in $36(73 \%)$ and vaginal delivery in 13 (26\%)patients, ICU admission required in $22(44 \%)$ patients, massive blood transfusion was given in $21(42 \%)$ patients, hysterectomy done in 8 (16\%) patients and dialysis in $4(8 \%)$ patients which was well compared with study done by Rattray et al in which caesarean done in $22(44 \%)$ and vaginal delivery in 27 $(66 \%)$ patients, ICU admission required in $20(41 \%)$ patients massive blood transfusion was given in 29 (59\%), hysterectomy done in $9(18 \%)$ patients and dialysis in 3 $(6 \%)$ patients. Need of massive blood transfusion is higher in haemorrhage $(85 \%)$ and abruption $(56 \%)$ compared to other cause. There was total 9 (18\%) hysterectomy were performed, 7 (78\%) due to intrapartum haemorrhage and 2 (22\%) rupture uterus. The composite severe maternal morbidity outcome in haemorrhage $(100 \%)$, abruption (63\%), preeclampsia (58\%), and AVH (33\%) (composite severe maternal morbidity outcome calculated on the basis of one or more of hysterectomy, ICU admission, blood transfusion $>5$ unit and ATN requiring dialysis). Out of the three most common causes (abruption, haemorrhage and preeclampsia), the composite maternal morbidity outcome was significantly more in women with haemorrhage than with abruption and preeclampsia. ${ }^{14}$

There were two twin pregnancy and total 51 infants were born by 49 mothers out of whom 37 (70\%) infants were survived, 13 (25\%) were died in utero. Study by Rattray et al, there were four twin pregnancy and total 53 infants were born by 49 mothers out of whom 39 (76\%) infants are survived, $12(24 \%)$ were died in utero. $21(53 \%)$ required NICU admission In present study out of 39 neonates, 7 (18\%) neonates died.

Out of 51 infants $39(76 \%)$ survived, while 12 (24\%) died in utero.

\section{NICU admission rate was $44 \%$,}

Almost all the patients were given blood and blood products (total number of blood 177 units and blood products 487 units). Rate of blood and blood products transfusion were highest in haemorrhage followed by abruption.

Our study highlights the high levels of maternal and perinatal mortality and morbidity associated with this obstetrical emergency. During the 3 years of this study there were 29 direct maternal deaths (deaths resulting from obstetric complications) in 15687 mothers delivered (a maternal mortality rate of 184 per 100000 ), and 8 of these 29 deaths were associated with DIC. Thus, the mortality rate directly related to DIC is 8 in 15678 ( 1 in 1960). Despite the overall low prevalence of DIC, we found a case fatality rate of $16 \%$ which means every 6 cases of DIC 1 was prone to death.

In our study, total 8 maternal deaths occurs in which only $3(25 \%)$ were booked patient and $5(75 \%)$ were emergency patients. Causes of death were haemorrhage (50\%), severe preeclampsia/eclampsia (25\%) and septicaemia (25\%) in my study indicating the blood loss remain leading cause of maternal morbidity and mortality.

The perinatal mortality rate was $38 \%$, stillbirth rate $24 \%$ and neonatal death rate $17 \%$. Placental abruption was associated with the worst perinatal outcome, with 11 of 18 $(61.1 \%)$ infants stillborn.

Limitations of the study are present study was a single centric study having a small sample size. So the results may not be reflected in the whole country.

\section{CONCLUSION}

DIC, as a marker of severe obstetrical complications, is associated with high levels of mortality and morbidity. Recognition of the antecedent causes and early investigation for and active management of DIC may help lower this morbidity. Despite its rarity, systematically searching for DIC should be added in treatment algorithms in the management of known obstetrical antecedents, because treatment delay may significantly worsen the prognosis. We should emphasize the low socioeconomical class and illiterate group for regular ANC and awareness about health care facilities to minimize the antecedent factors and complications of DIC. A timely referral to a physician or a haematologist will help sort out many of these adverse events and improve maternal outcome. For patients who are in less than tertiary care, a prompt transfer to a higher institution that has better facilities of specialist and blood bank could save lives. In particular the prompt management and arrest of postpartum haemorrhage before the need of massive transfusion and its attendant coagulopathy is one of the lessons from this study.

Funding: No funding sources

Conflict of interest: None declared

Ethical approval: The study was approved by the Institutional Ethics Committee

\section{REFERENCES}

1. Williams J, Mozurkewich E, Chilimigras J, Van De Ven C. Critical care in obstetrics: pregnancy-specific conditions. Best Pract Res Clin Obstet Gynaecol. 2008;22(5):825-46. 
2. Edmonds K, ed. Dewhurst's Textbook of Obstetrics and Gynaecology for Postgraduates. 5th edn. Wiley Blackwell; 1995:42.

3. Physiological changes during pregnancy. In: Sharma JB, ed. Textbook of obstetrics 2nd edn. APC Books; 2020:51.

4. DeLee JB. A case of fatal hemorrhagic diathesis, with premature detachment of the placenta. Am J Obstet Dis Women Child. 1901;44:785-92.

5. Kumar V, Abbas AK, Fauso N, Aster JC, eds. Robbins and Cotran pathologic basis of disease. 8th edn. Saunders, Philadelphia, PA; 2010:639-675.

6. Taylor Jr FB, Toh CH, Hoots KW, Wada H, Levi M. Towards definition, clinical and laboratory criteria, and a scoring system for disseminated intravascular coagulation. Thrombos Haemostas. 2001;86(11):1327-30.

7. Bick RL. Disseminated intravascular coagulation current concepts of etiology, pathophysiology, diagnosis, and treatment. Hematol Oncol Clin North Am. 2003;17:149-76.

8. Bick RL. Syndromes of disseminated intravascular coagulation in obstetrics, pregnancy, and gynecology. Objective criteria for diagnosis and management. Hematol Oncol Clin North Am. 2000;14:999-1044.

9. Kobayashi T, Terao T, Maki M, Ikenoue T. Diagnosis and management of acute obstetrical DIC. Semin Thrombos Hemostat. 2001;27:161.
10. Cunningham F, Lenovo K, Bloom S, Hauth J, Rouse D, Spong C, eds. Williams obstetrics. 23rd edn. New York NY: McGraw Hill; 2010:706-756.

11. Mehta P, Vaishnav U, Pawar M, Disseminated intravascular coagulation in obstetrics: a retrospective study. Int J Health Sci Res. 2016; 6(7):94-8.

12. Cunningham FG, Nelson DB. Disseminated intravascular coagulation syndromes in obstetrics. Obstet Gynecol. 2015;126(5):999-1011.

13. Bick RL, Adams T. Disseminated intravascular coagulation: etiology, pathophysiology, diagnosis and management. Med Counterpoint. 1974;6:38.

14. Rattray DD, O'Connell CM, Baskett TF. Acute disseminated intravascular coagulation in obstetrics: a tertiary centre population review (1980 to 2009). J Obstet Gynaecol Can. 2012;34(4):341-7.

15. Attar S, Boyd D, Layne E, McLaughlin JO, Mansberger AR, Cowley RA. Alterations in coagulation and fibrinolytic mechanisms in acute trauma. J Trauma Acute Care Surg. 1969;9(11):93965 .

Cite this article as: Kadikar SK, Diwan FJ, Topiwala $\mathrm{U}$, Agasiwala S. Study of pregnancy with disseminated intravascular coagulation. Int J Reprod Contracept Obstet Gynecol 2021;10:4220-5. 